\title{
Flash flood occurrence and relation to the rainfall hazard in a highly urbanized area
}

\author{
K. Papagiannaki, K. Lagouvardos, V. Kotroni, and A. Bezes \\ Institute of Environmental Research and Sustainable Development, National Observatory of Athens, Athens, Greece \\ Correspondence to: K. Papagiannaki (katpap@noa.gr)
}

Received: 2 April 2015 - Published in Nat. Hazards Earth Syst. Sci. Discuss.: 8 May 2015

Revised: 22 July 2015 - Accepted: 2 August 2015 - Published: 19 August 2015

\begin{abstract}
The paper examines the flash flood events that occurred over a decade in the Attica prefecture, the most urbanized region of Greece, with the aim of identifying triggering rainfall thresholds, as well as assessing the effect of rainfall upon the magnitude of the induced damages. The analysis incorporates rainfall records from a network of 28 surface meteorological stations and information on the spatial distribution of the flash flood events that is derived from the active database of damaging weather events maintained by the atmospheric modelling group of the National Observatory of Athens. The main findings concern firstly the relation between the flash flood impact, as measured by the fire service operations in flooded properties, and precipitation in various time intervals. In the period 2005-2014, 48 damaging flash flood events occurred in the target area and caused more than 3500 fire service operations in flooded properties. Most of the events are associated with maximum accumulated rainfall of more than $20 \mathrm{~mm}$ in $24 \mathrm{~h}$ and $3 \mathrm{~mm}$ in $10 \mathrm{~min}$. However, the flash flood impact intensity, as measured by the number of the fire service operations per event, increases significantly above the levels of $60 \mathrm{~mm}$ in $24 \mathrm{~h}$ and $10 \mathrm{~mm}$ in $10 \mathrm{~min}$. Secondly, graphs of rainfall intensity versus duration are developed for 15 sub-areas of Attica in order to define rainfall intensity thresholds for flood triggering at a more local level. It is shown that conclusions regarding the reliability of the estimated thresholds should take into account the representativity of the rain gauges, which is determined by the local network's density, the gauges' location and record length.
\end{abstract}

\section{Introduction}

Flooding caused by heavy rainfall is a weather-related hydrological hazard associated with significant economic losses, human fatalities and adverse effects to society and the ecosystem. Even though floods do not appear with the catastrophic power of other natural hazards, such as earthquakes, their overall impact on society and the economy is very serious. In Europe, numerous floods and flash floods occur each year, accounting for $40 \%$ of the total economic damages due to natural hazards for the period 1989-2008 (CRED, 2009). The societal impact of flash floods varies and depends on the hazard intensity and the vulnerability of the affected area as measured by its topographic and demographic features, the quantity and quality of the materials exposed, the anthropogenic interventions and the effectiveness of the prevention measures taken by the local authorities (Tsakiris, 2014). Interestingly, extreme flash floods in the Mediterranean countries tend to be greater in magnitude compared to the inner continental countries (Gaume et al., 2009), while they occasionally produce catastrophic damages (Llasat et al., 2013; Lastoria et al., 2006). Furthermore, analysis of the spatial distribution of flood events in Mediterranean countries has shown that the urbanized environment increases vulnerability and flood risks (Llasat et al., 2009).

As the risk and consequently the societal impact of the weather hazard is a function of the hazard's magnitude and the local vulnerability (Špitalar et al., 2014), the assessment of damages caused by flash floods in urban areas integrates a variety of factors related to the weather and hydrological hazard and to urban-specific characteristics. Compared to the damages that are caused by riverine or coastal flooding, damages in urban areas are much more dependent on anthropogenic and demographic factors that increase flood risk and 
are difficult to assess, such as the land development that limits water infiltration and increases run-off (Du et al., 2015; Kandilioti and Makropoulos, 2012) and population density associated with the amount of people and property exposed to risk (Amaro et al., 2010; Llasat et al., 2009). Recently, Barbería et al. (2014) discussed rainfall intensity thresholds in conjunction with regional vulnerability indicators, namely the population density, which is directly linked to the type of urbanization and the land use (Llasat et al., 2009). This study investigates the correlation between several rainfall parameters and the number of requests received by the meteorological services related to insurance claims, which have been already proved to be a good indicator of social impact in the study of Amaro et al. (2010). The urban area discussed is the city of Barcelona, and results for the period 2008-2011 show that there is a statistically significant correlation between short-duration rainfall intensities and the requests related to insurance claims. The high value of this study is that it successfully introduces an alternative measure of the material damages, namely the number of insurance claims, compared to monetary measures such as the compensations paid by the implicated authorities and the insurance companies (Llasat et al., 2008; Lastoria et al., 2006; Jonkman, 2005), which may constitute a better indicator of the impact intensity of the event but are rather hard to find and often cover only part of the overall damage.

As mentioned before, Barbería et al. (2014) also assess the rainfall intensity factor as an indicator of the flash flood hazard. The authors suggest specific thresholds of precipitation and relate them to the impact intensity of the flash flood events. In search of the flood-triggering factors, other studies have also used the accumulated rainfall and/or the rainfall intensity as main indicators of the flash flood occurrence and magnitude. Cannon et al. (2008) and Guzzetti et al. (2008) developed rainfall intensity-duration thresholds for the occurrence of debris flows, landslides and floods. This methodology was later adapted by Diakakis (2012) to examine the role of storm totals, peak and average rainfall intensity, and moisture conditions in flood triggering in northeast Attica, in Greece, for the period 1993-2008. The author found a significant correlation between peak storm intensity and flood triggering and presented rainfall thresholds above which flooding is highly probable. Bracken et al. (2008) studied a semiarid area in south-east Spain and found that floods in the period 1997-2003 have been more highly related to the total rainfall than to the intensity of a storm, although intensity controls the nature and timing of the flood process.

Rainfall thresholds have been also proposed as indicators of early warnings of flash floods. Martina et al. (2006) introduced a methodology for issuing flood warnings by directly comparing the quantitative precipitation forecast to a critical rainfall threshold value, incorporating initial soil moisture conditions as well as expected costs, without the need of real-time meteorological and hydrological forecasting models. In Norbiato et al. (2009) flash flood warning methodolo- gies are based on hydrological models, but they also integrate the flash flood guidance (FFG) method, that is, the rainfall threshold approach on which the US National Weather Service relies for issuing warnings (Georgakakos, 2006). FFG refers to the volume of rain of a given duration necessary to cause minor flooding of small streams (Carpenter et al., 1999). Price et al. (2011a, b) recognized that flash floods are among the costliest natural hazards around the globe and used lightning data to better understand and predict flash floods in the Mediterranean. Over the highly urbanized area of Athens, flash flood forecasting has been explored based on an integrated hydro-meteorological system by Koussis et al. (2003), with promising results.

The present paper contributes to the research on the impact and triggering factors of flash floods in Greece and the Mediterranean, introducing an analysis of the flash flood events that occurred during the 10-year period 2005-2014 in the Attica basin, the most urbanized and densely populated region of the country. The main targets are to detect systematically affected areas within Attica, define and assess flash flood hazard indicators, and discern flash flood patterns and possible rainfall thresholds related to the occurrence of flash floods as well as to the magnitude of the adverse impact. The possibility of using the estimated rainfall thresholds to establish alert systems to warn communities of impending floods is also discussed.

For the analysis, the database of high-impact weather events developed by the atmospheric modelling group of the National Observatory of Athens (NOA) was used (Papagiannaki et al., 2013). The database provides information about all the high-impact weather events that have occurred since 2001 and is systematically updated. The number of the fire service operations during flooding events is also incorporated in the analysis and studied in relation to the rainfall parameters, in search of a reliable impact indicator that is systematically and officially recorded. In the context of the present analysis, regional vulnerability to the flash flood hazard is partly addressed by examining the frequency of flooding events in conjunction with the amount of rainfall needed for a place to flood and by discussing the relevance of topographic and vulnerability-related factors, namely the population density, to the frequency of flooding events.

This paper is structured as follows: in Sect. 2 (Data collection), the sources of the high-impact weather events that have occurred in Greece, the meteorological observations and the fire service operations are presented in detail. In Sect. 3 (Methodological issues), the criteria for the specification of the sub-areas studied are described. Then the reasoning behind the use of specific meteorological parameters is explained and the methodology for estimating rainfall thresholds for flood triggering is introduced. In Sect. 4 (Urban flash flood analysis), results that have been derived from the correlation between precipitation parameters and the fire service operations, as well as from the analysis of the rainfall intensity for various accumulated durations, are analysed and dis- 


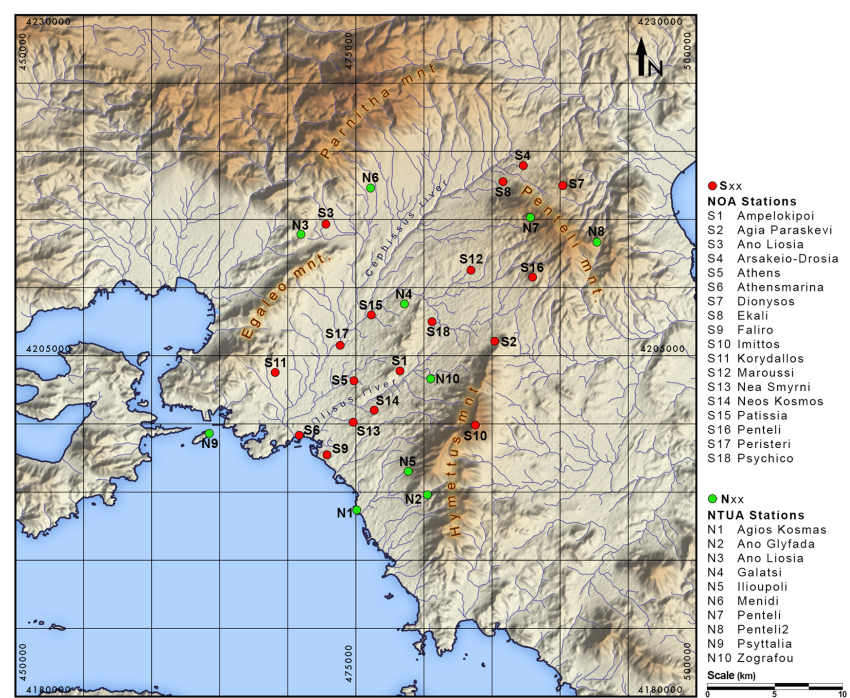

Figure 1. Map of the Greek target area (Athens and suburbs) and locations of the 28 surface meteorological stations. Stations are named by the municipalities they are located in. (Created using QGIS and SRTM-v3 elevation data. Projection GGRS87. Area easting: 450 000-500 $000 \mathrm{~m}$. Area northing: $4180000-4230000 \mathrm{~m}$. Copyright NOA-IERSD.)

cussed. The analysis concerns the entire target area as well as 15 additional sub-areas, thus providing evaluation of the rainfall thresholds for flood triggering at a more local level. Finally, in Sect. 5 (Concluding remarks), main conclusions and future perspectives are given.

\section{Data collection}

The target area comprises the city of Athens, which is the capital of Greece, and the suburbs, which are subdivided in municipalities. From a geographical point of view, the target area - hereafter called Athens-suburbs - depicted in Fig. 1, is located in the centre of the Attica region, in the central-east of the Greek mainland, bordering the southern part of the Aegean Sea and surrounded by four mountains: Aigaleo and Parnitha in the west-north-west, and Penteli and Hymettus in the east-south-east. Two rivers flow through the Athens plain. The large one, the river Kifissos, is the main water stream of Athens, follows a NNE-SSW flow direction and has produced serious flooding events in the past. Since 2002, it has been systematically monitored to prevent unpredictable overflows. The second and smaller river, Ilissos, is found in the east part and has been built up to a great extent.

In what concerns the frequency and magnitude of damages caused by weather-related hazards, Attica is by far the most affected region in the country (Papagiannaki et al., 2013; Diakakis et al., 2012), suffering particularly from flash floods, which cause at times serious damages. According to the latest report of the Hellenic Association of In- surance Companies (HAIC, 2015), the 13 most damaging flash flood events that occurred in Greece during the period 1993-2014 caused economic losses of about EUR 93 million, most of which correspond to claims for compensations in Attica. Vulnerability of the Attica prefecture to flash floods is highlighted in the study of Papagiannaki et al. (2013), which introduced the database of high-impact weather events that have occurred in Greece since 2001, followed by the spatial and temporal distribution of the events for the period 2001-2011. A simplified version of the database is available online on the site of the atmospheric modelling group of the National Observatory of Athens (http://www. meteo.gr/weather_cases.asp). A geographical presentation of the recorded weather events is also available online (http:// www.meteo.gr/meteoplus/weatherevents.cfm). The database is systematically updated with every new weather event that generates damages in Greece and includes so far more than 300 cases, which are classified according to their weather and impact intensity. According to the updated database, during the period 2001-2014, 91 flash flood events affected Attica, 48 of which occurred in the Athens-suburbs area, causing buildings, infrastructure and vehicle damages; large-scale transport disruption; flooded road; and in some cases human fatalities. The database, besides the weather and impact classification, also encloses detailed information for each weather event, namely their geographical distribution, the location and type of damages, meteorological data, and detailed references in the press. Thus, it has been used for the purposes of the present analysis in order to define the flash flood events that occurred in the target area and the location of the respective damages.

To address the vulnerability of the specific areas affected by flash floods within the Athens-suburbs region, weather and impact indicators are both incorporated in the present analysis. Meteorological data used in the analysis derive from 28 surface meteorological stations (Fig. 1) spread in the Athens-suburbs region. The atmospheric modelling group of the National Observatory of Athens operates 18 of these stations, while the rest are operated by the Laboratory of Hydrology and Water Resources Management of the National Technical University of Athens (NTUA) and rainfall measurements are freely available to the public. The meteorological stations provide $10 \mathrm{~min}$ observations of various meteorological parameters such as temperature, pressure, humidity, wind velocity and direction, rain and rain intensity. Based on the availability of rain observations from the NOA and NTUA meteorological station networks in Athens, the present analysis is limited to the 10-year period 2005-2014.

Data on actual financial losses due to flash floods, such as the monetary compensations paid by the implicated authorities and the insurance companies, were not available during this study. Therefore, following the concept of Barbería at al. (2014), the impact of each flash flood event is assessed using the number of the fire service operations that took place due to citizens' calls for flooded properties. Daily data on 
the operations in flooded properties derive from the Statistical Department of the Hellenic Fire Service and concern the entire Attica region for the period 2003-2013. For the year 2014, the respective data have been found in press articles; thus they may deviate from the official ones, being underestimated only to a small degree. Even though the number of operations during an event concerns the entire region of Attica, the description of the events included in the database is extensive enough to reproduce with high certainty the map with the specific areas affected during each event. The data provided by the fire service are exhaustive, while all the events with more than 10 operations have been included in the NOA database and, thus, are considered in the present analysis. The amount of fire service operations per event derives from the aggregation of the number of operations per day that took place during the days of an event. It should be noted that one operation may concern more than one building; thus the actual number of flooded properties is not known. Judging from the respective press that usually reports the number of citizens' calls, the amount of flooded properties can be as much as 4 times greater than the number of operations in the same event. However, due to the uncertainty in the actual number of properties, this study uses the number of operations which is systematically recorded and therefore highly reliable.

\section{Methodological issues}

\subsection{Specification of sub-areas}

In order to account for the regional characteristics and vulnerability (Barberia et al., 2011), specific sub-areas within the Athens-suburbs region are also studied separately. Methodological issues concern the division of the Athenssuburbs region into sub-areas that can be considered to be adequately covered by a group of specific rain gauges, the specification of the particular areas that were influenced by each flash flood event and the specification of the most representative rain gauges for each flash flood event. Difficulties emerge due to the spatial distribution and the short lifetime of some of the gauges that result in lack of good representation at municipality level. Thus, an optimum exploitation of the existing rain gauges is required in order to match gauges with sub-areas and then with the flash flood events.

The division of the Athens-suburbs region in secondary areas follows geographical criteria and is guided by the location of mountains and river streams, and an important criterion for the determination of each sub-area is the presence of rain gauges located within its perimeter. As Fig. 2 shows, the shaped sub-areas are covered by three to five gauges. The name of each sub-area derives from the respective municipality that covers the major part of it. The formation of the sub-areas based on the above-mentioned criteria rather than the administrative boundaries of the municipalities enables the analysis to be as effective as possible based on a suffi- cient number and spatial distribution of gauges. In what concerns the specification of the areas influenced by each flash flood event, as explained in Sect. 2, the descriptive information included in the NOA database of weather-related events has been used.

\subsection{Maximum precipitation and fire service data}

In the context of the present analysis, impact indicators are studied in conjunction with hazard parameters. Following the concept of the most recent and relevant articles (Barbería et al., 2014; Diakakis, 2012), precipitation parameters have been used in the analysis, namely the rain records in various time intervals. For each event, the absolute maximum precipitation is calculated based on the observations of the representative rain gauges. Maximum precipitation in different time intervals is then correlated to the number of the fire service operations per event in order to assess the effect of the rainfall intensity on the magnitude of the societal impact. The statistical dependence is measured with Spearman's rank correlation coefficient, $\rho$, which does not assume normality of data. Also, distributions of the frequency of the operations by month and by rainfall level are presented to complement the discussion.

A methodological limitation is the fact that the number of the fire service operations per event, which is given as a total for the entire target area, cannot be distributed to the specific sub-areas affected in each case. Thus, the local impact intensity cannot be measured by the number of operations. Instead, local vulnerability is assessed firstly based on the frequency of damaging flash flood events per area and secondly by the examination of the hazard intensity related to the flood occurrence in each specified area.

\subsection{Rainfall thresholds}

To estimate possible rain thresholds related to flood triggering in each sub-area, the methodology followed by $\mathrm{Di}$ akakis (2012) has been applied. The author developed rainfall intensity-duration thresholds for the occurrence of floods in Marathonas, Greece, and by plotting peak rainfall intensities of various time intervals against their respective durations and then defining rainfall intensity thresholds above which flooding is most likely to occur. Accordingly, in the present study, the graphs of peak rainfall intensities of various time intervals $(10,30$ and $60 \mathrm{~min} ; 2,3,12$ and $24 \mathrm{~h}$ ) vs. duration have been plotted for each area in order to investigate possible rainfall thresholds above which flooding is most likely to occur. For that, all the time series records of 10 min precipitation have been used. It should be noted that a rainfall event - independently of whether flooding occurred - is considered to start if more than $24 \mathrm{~h}$ without rain has proceeded. Also, the maximum accumulated rain in 10, 30 and $60 \mathrm{~min}$, and 2, 3, 12 and $24 \mathrm{~h}$ of each rainfall event is calcu- 


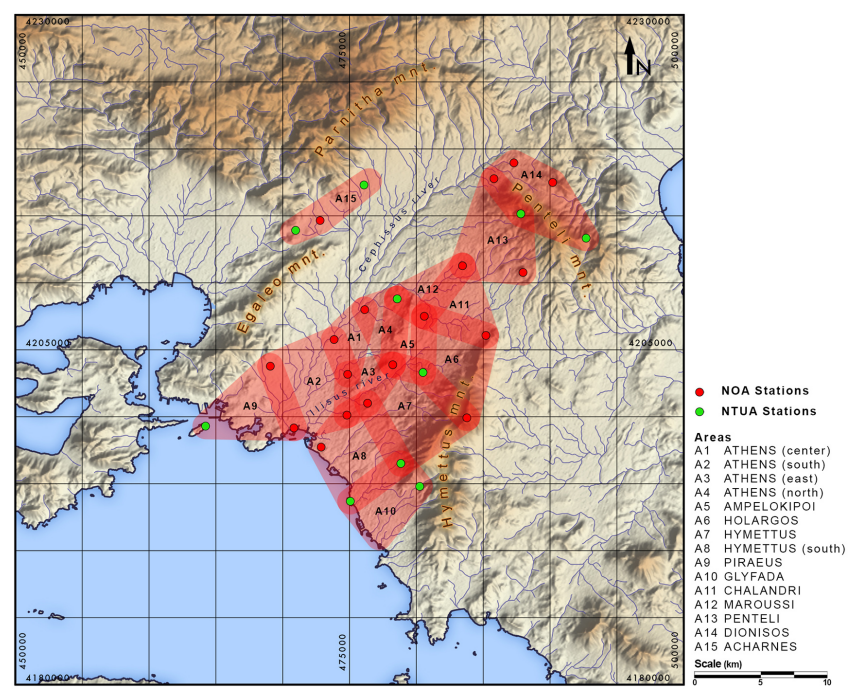

Figure 2. Division of Athens-suburbs region in 15 sub-areas. The representative rain gauges in each sub-area are also shown with red (NOA stations) and green (NTUA stations) bullets. (Created using QGIS and SRTM-v3 elevation data. Projection GGRS87. Area easting: $450000-500000 \mathrm{~m}$. Area northing: 4 $180000-4230000 \mathrm{~m}$. Copyright NOA-IERSD.)

lated as the maximum moving sum, through time steps of 10 , 30 and $60 \mathrm{~min}$, and 2, 3, 12 and $24 \mathrm{~h}$ respectively.

\section{Urban flash flood analysis}

During the period 2005-2014, 48 flash flood events occurred in the Athens-suburbs region and caused more than 3500 fire service operations in flooded properties. The maps in Fig. 3a and $b$ highlight the spatial distribution of flash flood events in the Athens-suburbs region and population density respectively. Both maps display the distribution at a municipality level due to the respective availability of population data. Comparison between the two maps leaves no doubt as to the importance of the population distribution to the regional vulnerability. The municipality of Athens, which is the most densely populated area, with around 17000 inhabitants per $\mathrm{km}^{2}$, was the most frequently affected area, with 20 events recorded during the study period. High population density is naturally related to intense urbanization, which results in an increase in impervious surface and, consequently, in total run-off volumes. Besides that, the geographical location of Athens also contributes to the increased vulnerability to the rainfall hazard. Athens is located in the centre of the Attica basin, where run-off from the higher sloped areas end.

\subsection{Relation between hazard and impact indicators}

Table 1 includes the areas affected by each flash flood, following the numbering of the specific sub-areas shown in Fig. 2, the number of the fire service operations and the
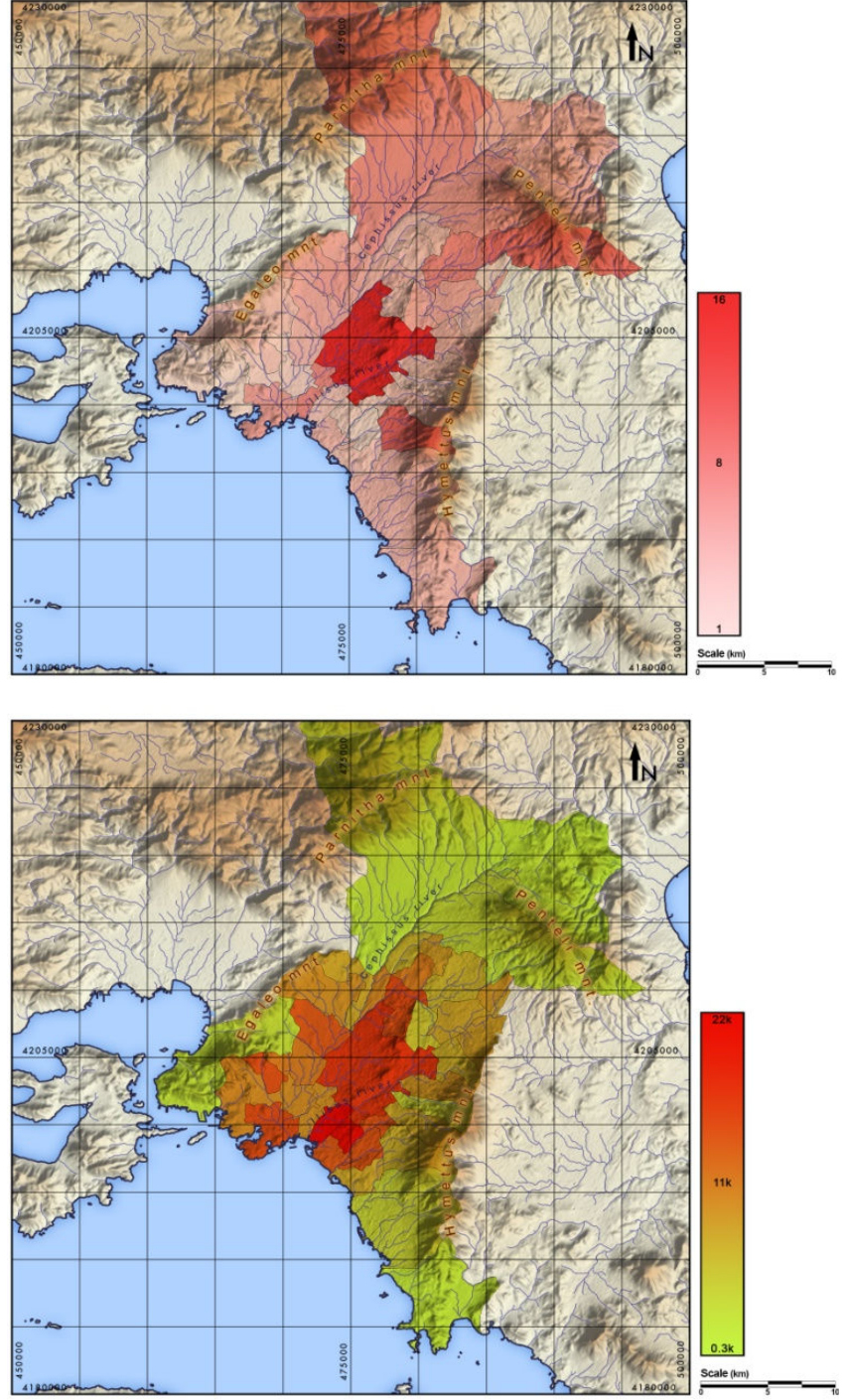

Figure 3. (a) Number of flash flood events for each one of the 15 sub-areas of the Athens-suburbs region. (b) Population density (people per sq. km of land area). (Created using QGIS and SRTMv3 elevation data. Projection GGRS87. Area easting: 450000 $500000 \mathrm{~m}$. Area northing: $4180000-4230000 \mathrm{~m}$. Copyright NOAIERSD.)

maximum precipitation (in $\mathrm{mm}$ ) in various time intervals per event. Most of the events affected as many as 6 sub-areas, and only 3 out of the 48 events were actually spread over a large part of the Athens-suburbs region.

The quantile distribution plots of the maximum $24 \mathrm{~h}$ accumulated rain (R24) and the maximum 10 min accumulated rain (R10) are displayed in Fig. 4a and b, showing that $50 \%$ of events are related to R24 between 30 and $60 \mathrm{~mm}$ and to $\mathrm{R} 10$ between 6.5 and $14 \mathrm{~mm}$. Rain in $24 \mathrm{~h}$ is more indicative of the ground saturation effect, while R10 is more indicative of the rain intensity effect. There have been only two damag- 
Table 1. Areas affected, number of fire service operations and rainfall (in $\mathrm{mm}$, at various accumulation durations) per flash flood event.

\begin{tabular}{|c|c|c|c|c|c|c|c|}
\hline Date & Areas ${ }^{1}$ & Operations & $\mathrm{R} 10^{2}$ & $\mathrm{R} 30^{2}$ & $\mathrm{R} 60^{2}$ & $\mathrm{R} 12^{2}$ & $\mathrm{R} 24^{2}$ \\
\hline 03/07/2005 & $7,8,9,10$ & 35 & 11.6 & 25.6 & 33.4 & 35.6 & 35.6 \\
\hline 22/09/2005 & $1,2,4,7,8,9$ & 168 & 13.4 & 28.8 & 37.6 & 53.0 & 55.2 \\
\hline $17 / 11 / 2005$ & 7,8 & 73 & 8.0 & 16.4 & 19.8 & 76.8 & 82.0 \\
\hline $24 / 11 / 2005$ & $4,7,8,10,12$ & 245 & 15.8 & 44.2 & 65.4 & 105.4 & 122.8 \\
\hline $28 / 12 / 2005$ & 4,12 & 31 & 4.2 & 8.4 & 9.4 & 15.4 & 17.2 \\
\hline 05/02/2006 & $1,7,8$ & 23 & 10.6 & 22.2 & 29.6 & 52.0 & 52.0 \\
\hline $11 / 03 / 2006$ & 4 & 11 & 7.6 & 22.2 & 24.8 & 30.2 & 35.0 \\
\hline 18/09/2006 & $1,4,5,12$ & 24 & 11.4 & 23.6 & 28.0 & 28.2 & 28.2 \\
\hline 20/09/2006 & $1,3,4,11$ & 11 & 2.2 & 5.4 & 7.6 & 13.0 & 13.0 \\
\hline 21/09/2006 & $1,4,5,6,12$ & 55 & 12.4 & 29.8 & 34.0 & 34.2 & 34.2 \\
\hline $10 / 10 / 2006$ & 14 & 85 & 13.6 & 23.2 & 30.6 & 82.9 & 132.9 \\
\hline 30/10/2006 & $11,12,13,15$ & 32 & 3.0 & 8.4 & 15.4 & 94.2 & 110.8 \\
\hline $24 / 05 / 2007$ & 15 & 130 & 20.6 & 41.8 & 55.6 & 71.6 & 72.2 \\
\hline 21/10/2007 & $1,3,5$ & 80 & 11.4 & 20.4 & 23.6 & 46.2 & 46.4 \\
\hline $17 / 11 / 2008$ & 2,9 & 24 & 7.0 & 16.8 & 25.4 & 42.6 & 42.6 \\
\hline $12 / 12 / 2008$ & $1,2,3,8,9$ & 27 & 9.4 & 15.6 & 16.6 & 21.0 & 23.2 \\
\hline 04/07/2009 & $4,5,12$ & 42 & 9.4 & 18.8 & 25.4 & 28.8 & 28.8 \\
\hline $31 / 08 / 2009$ & 15 & 20 & 15.2 & 27.8 & 28.8 & 29.0 & 29.0 \\
\hline 25/10/2009 & 13 & 25 & 5.2 & 8.4 & 11.4 & 27.0 & 33.6 \\
\hline 03/11/2009 & 12 & 18 & 4.6 & 9.6 & 14.4 & 20.4 & 22.4 \\
\hline $15 / 12 / 2009$ & 15 & 24 & 6.6 & 14.4 & 19.6 & 37.4 & 37.4 \\
\hline 03/07/2010 & $1,6,7$ & 25 & 18.4 & 33.4 & 38.4 & 39.2 & 39.2 \\
\hline 26/07/2010 & 11,13 & 16 & 11.0 & 23.8 & 29.4 & 45.6 & 45.6 \\
\hline 27/10/2010 & $1-7,9,11,12$ & 52 & 16.4 & 28.4 & 30.8 & 36.0 & 36.0 \\
\hline $12 / 11 / 2010$ & $6,7,8$ & 16 & 11.0 & 15.2 & 16.2 & 28.0 & 32.0 \\
\hline 03/02/2011 & $7,8,10$ & 210 & 3.4 & 9.4 & 18.0 & 88.0 & 99.6 \\
\hline 24/02/2011 & 6,11 & 54 & 2.6 & 5.6 & 7.4 & 29.8 & 41.0 \\
\hline $12 / 06 / 2011$ & $1,2,3$ & 26 & 9.6 & 24.6 & 32.4 & 36.4 & 36.4 \\
\hline 14/06/2011 & 15 & 37 & 11.0 & 22.8 & 33.8 & 35.2 & 35.2 \\
\hline 10/10/2011 & 3 & 35 & 2.6 & 5.8 & 8.4 & 23.0 & 28.8 \\
\hline 06/02/2012 & $1,2,3,7,9$ & 70 & 12.2 & 25.2 & 39.2 & 65.2 & 72.0 \\
\hline 18/04/2012 & 2,8 & 10 & 5.0 & 10.2 & 18.6 & 32.6 & 32.6 \\
\hline 30/11/2012 & 13,14 & 30 & 20.8 & 34.8 & 39.2 & 54.0 & 55.2 \\
\hline $18 / 12 / 2012$ & $1,2,8,9$ & 36 & 16.0 & 25.0 & 29.4 & 31.0 & 43.8 \\
\hline 29/12/2012 & 6,14 & 118 & 3.2 & 4.8 & 8.4 & 161.6 & 186.2 \\
\hline $16 / 01 / 2013$ & 2,15 & 17 & 6.8 & 15.4 & 24.4 & 39.6 & 40.0 \\
\hline $22 / 02 / 2013$ & $1-9,11,12,15$ & 632 & 15.6 & 35.0 & 46.4 & 95.4 & 97.6 \\
\hline $12 / 06 / 2013$ & 11,12 & 26 & 19.6 & 31.8 & 42.6 & 50.4 & 50.8 \\
\hline $11 / 11 / 2013$ & $1,2,3$ & 90 & 10.0 & 23.0 & 39.0 & 53.2 & 53.2 \\
\hline 20/11/2013 & 10 & 22 & 4.8 & 12.4 & 14.8 & 27.4 & 27.4 \\
\hline $24 / 11 / 2013$ & $1,2,3$ & 12 & 8.0 & 12.6 & 19.6 & 26.8 & 26.8 \\
\hline 25/01/2014 & $1,2,3,6,7$ & 100 & 16.4 & 34.6 & 35.6 & 37.6 & 42.0 \\
\hline 28/01/2014 & $1,2,4$ & 20 & 10.0 & 17.2 & 31.2 & 56.4 & 62.2 \\
\hline 19/07/2014 & $3,7,8,10$ & 50 & 16.6 & 41.2 & 51.6 & 55.4 & 55.4 \\
\hline 07/09/2014 & 13 & 25 & 12.0 & 31.6 & 46.6 & 50.6 & 50.8 \\
\hline $15 / 09 / 2014$ & 11,12 & 20 & 15.6 & 27.6 & 28.6 & 28.6 & 28.8 \\
\hline $16 / 09 / 2014$ & $1,7,14$ & 60 & 10.2 & 24.6 & 26.4 & 28.4 & 28.8 \\
\hline $24 / 10 / 2014$ & $1-4,9,12,15$ & 500 & 14.0 & 35.6 & 43.6 & 71.8 & 74.0 \\
\hline
\end{tabular}

ing flash flood events during which less than $20 \mathrm{~mm}$ of R24 was recorded and three events with $\mathrm{R} 10$ less than $3 \mathrm{~mm}$.

To better comprehend the role of the hazard magnitude, Fig. 5a and $\mathrm{b}$ display the number of events and operations for various ranges of R24 and R10. Due to the high frequency of events associated with R24 between 30 and $60 \mathrm{~mm}$, most of the fire service operations correspond to this rainfall range (Fig. 5a). However, the impact intensity, measured as the 

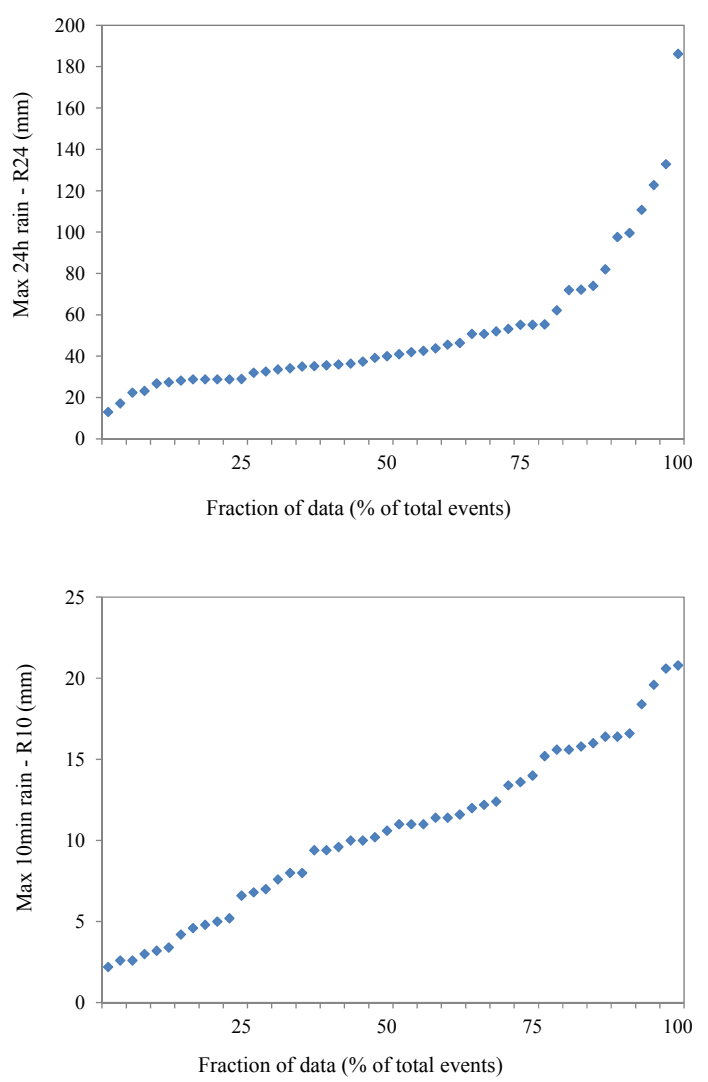

Figure 4. Quantile distribution plots for (a) the maximum $24 \mathrm{~h}$ accumulated rain (R24) and (b) the maximum $10 \mathrm{~min}$ accumulated rain (R10) observations (in $\mathrm{mm}$ ).

average number of operations per event, is much higher for R24 above $60 \mathrm{~mm}$. On average, 42 operations per event have been recorded for R24 between 30 and $60 \mathrm{~mm}$, while 160 operations per event correspond to R24 between 60 and $90 \mathrm{~mm}, 291$ operations per event to R24 between $90 \mathrm{~mm}$ and $120 \mathrm{~mm}$, and 165 operations per event to R24 between 120 and $150 \mathrm{~mm}$. Therefore, the rainfall hazard, when examining the entire Athens-suburbs region, increases significantly above the level of $60 \mathrm{~mm}$ for R24. Furthermore, the distribution and impact of flash flood events based on the level of $\mathrm{R} 10$ (Fig. 5b) show that the most common R10 records are in the range of $10-15 \mathrm{~mm}$, while the impact intensity increases significantly above $10 \mathrm{~mm}$. Particularly for R10 range 15 $20 \mathrm{~mm}$, the average number of operations per event was over 120 for the examined period.

In what concerns the temporal distribution, Fig. 6 shows that autumn was the season with the highest frequency of flash flood events, as well as with the highest number of fire service operations, followed by winter. Autumn in Greece is actually the season with the highest frequency of rainfall and the highest accumulated rainfall, particularly in what concerns the mainland (Jansa et al., 2014; Lagouvardos and Kotroni, 2007; Kotroni et al., 1999; Lagouvardos et al.,
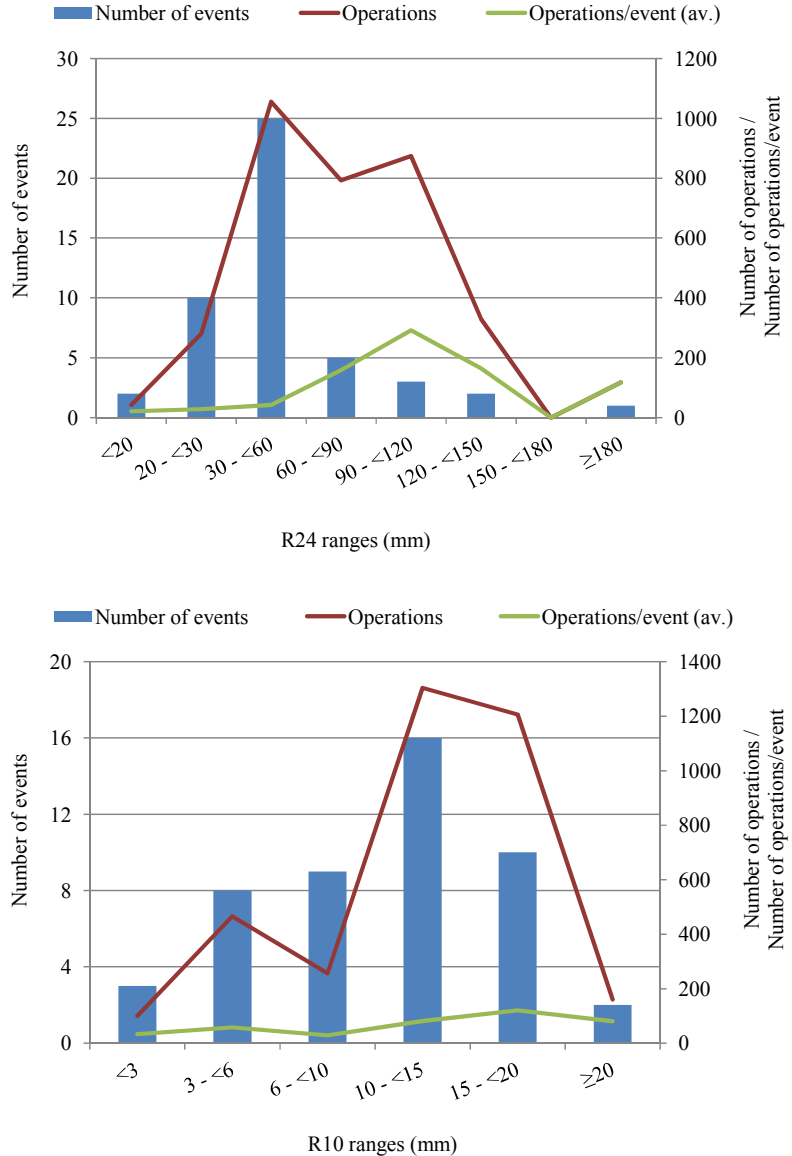

Figure 5. Number of events, fire service operations and average number of operations per event for various ranges of maximum (a) $24 \mathrm{~h}$ (R24) and (b) $10 \mathrm{~min}$ (R10) accumulated rain (in mm).

1996). This is in accordance with previous analysis of historical floods in Greece, which concluded that autumn was the season with the richest flood record for the period 1880-2010 (Diakakis et al., 2012). The high impact of February flash floods is mostly due to one event that occurred in 2013 and provoked more than 600 operations. Similarly, one event that occurred in October of 2014 caused 500 operations. Overall, the highest R24 record was $186 \mathrm{~mm}$, observed during an event that caused 118 operations by the fire service and had a quite low R10 (3.2 $\mathrm{mm}$ in $10 \mathrm{~min}$ ). Actually, the correlation between R24 and R10 is weak $(\rho=0.32, p<0.05)$, while most of the high R10 values relate to R24 being less than $70 \mathrm{~mm}$.

Correlation between the number of operations and the maximum rainfall in the various time intervals has been investigated in order to detect the hazard parameter that best relates to the magnitude of the impact. As illustrated in Table 2 , the number of operations is strongly correlated with the maximum rainfall in $24 \mathrm{~h}, \mathrm{R} 24,(\rho=0.61)$, while the strength of correlation drops with the decrease in the time interval. The fact that R24 is the precipitation parameter that 


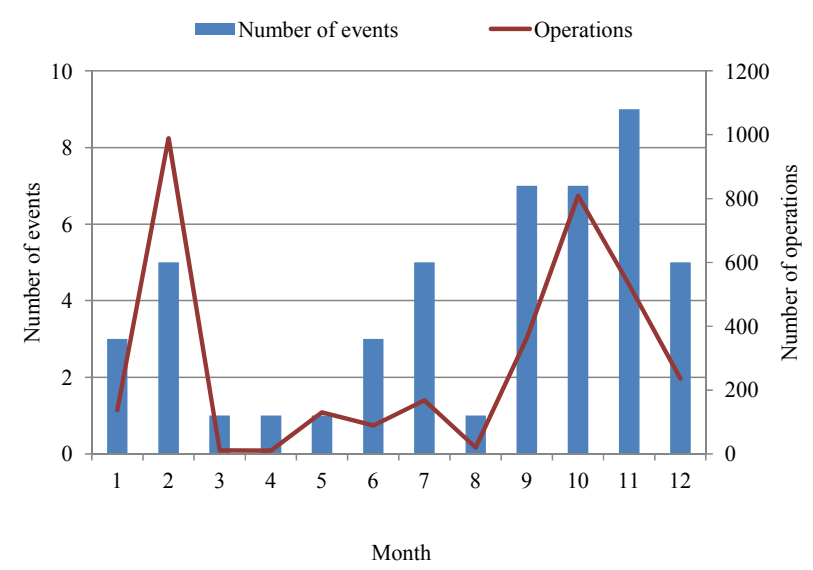

Figure 6. Monthly distribution of the number of flash flood events that occurred in the Athens-suburbs region and fire service operations.

Table 2. Correlation (Spearman's rank coefficient, $\rho$ ) between the number of the fire service operations and the maximum rainfall in various time intervals.

\begin{tabular}{lrrrrr}
\hline $\begin{array}{l}\text { Maximum rainfall } \\
\text { (time interval) }\end{array}$ & $\begin{array}{r}\mathrm{R} 24 \\
(24 \mathrm{~h})\end{array}$ & $\begin{array}{r}\mathrm{R} 12 \\
(12 \mathrm{~h})\end{array}$ & $\begin{array}{r}\mathrm{R} 60 \\
(60 \mathrm{~min})\end{array}$ & $\begin{array}{r}\mathrm{R} 30 \\
(30 \mathrm{~min})\end{array}$ & $\begin{array}{r}\mathrm{R} 10 \\
(10 \mathrm{~min})\end{array}$ \\
\hline $\begin{array}{l}\text { Operations } \\
\text { Athens-suburbs }\end{array}$ & $0.61^{* * *}$ & $0.58^{* * *}$ & $0.40^{* *}$ & $0.37^{* *}$ & $0.31^{*}$ \\
Athens city & $0.85^{* *}$ & $0.85^{* *}$ & $0.85^{* *}$ & $0.83^{* *}$ & $0.69^{*}$ \\
\hline${ }^{*} p<0.05,{ }^{* *} p<0.01,{ }^{* * *} p<0.001$. & & & &
\end{tabular}

best represents the magnitude of the impact, at least when considering only the flooded properties, is reasonable since the calculation concerns the entire Athens-suburbs region, which includes, however, areas of unique regional vulnerability that may respond differently to rainfall of the same intensity. These differences, however, tend to become smoother as the accumulation period increases and the various smallscale intensities are normalized.

The significance of the regional vulnerability should be further studied by focusing on the sub-areas of the Athenssuburbs region. However, what is known with certainty is the number of operations per event as well as the areas the event affected, while the exact allocation of the operations is not known. Therefore, to minimize the uncertainty in the estimated results, we attempted to study separately only the city of Athens, focusing on the events that affected the centre, south and east of the municipality of Athens together. This is actually the most populated region in Attica and Greece, exhibiting also the highest frequency of damaging flash flood events, while the network of rain gauges is denser compared to the other areas examined. Some of the events incorporated in the specific analysis have also affected surrounding areas, thus there might be an overestimation of the assigned number of operations. However, when focusing on these neighbouring areas together, the number of operations is strongly correlated with all the durations of accumulated precipita- tion ( $\rho$ 0.69-0.85), the R10 included. Correlation results are included in Table 2. It is obvious that analysis on a more local scale permits better capturing the effect of the volume of rainfall to the magnitude of impact and allows for consideration of short-duration rainfall in the examination of the flash flood impact, as long as a sufficient network of rain gauges exists.

\subsection{Rainfall intensity thresholds for flood triggering, at regional level}

The results of the previous section raise the question of whether rainfall intensity thresholds can be defined above which flooding is probable or even certain for some areas and of whether short-duration rain intensities can reliably indicate risk of flooding. For that, the entire time series of precipitation records (not only of the flood events) for different accumulation durations have been used and the respective peak rainfall intensities are plotted, following the methodology introduced by Cannon et al. (2008) and Diakakis (2012). Graphs of rainfall intensity versus duration have been developed for each one of the sub-areas specified in Fig. 2 and illustrate the peak rainfall intensities recorded by the most representative rain gauges. Flash flood occurrence is highlighted in red. As expected, rainfall intensity is falls as accumulation duration increases. The goal is to distinguish, if possible, two clear thresholds (denoted by the black lines in Fig. 7) that divide the graph into three parts: (a) the lower one includes peak intensity values that did not lead to flooding throughout the studied period; (b) the middle part includes peak intensities that either did or did not lead to flooding; and (c) the upper part includes peak intensities that always led to flooding.

Results vary considerably depending on the area examined and the local vulnerability, as well as on the density, location and record length of the representative rain gauges. Graphs on which extremely low rainfall intensities are shown to correspond to flood occurrence indicate a poor relationship between the flooding event and one or more of the rain gauges that represent the studied area. One reason for this inconsistency may be the long distance of the gauge from the flooded area; it is even possible for a flash flood to be caused by the run-off of distant intensive rainfall occurring in higher terrain around the affected area.

The distribution of the rainfall intensity values in the short durations varies a lot between areas; as accumulation time increases, peak intensities tend to be more similar. Obviously, areas with high frequency of flash flood events tend to give more explicable outcomes. These are mainly the areas around the centre of Athens (centre, east and south of Athens) and secondarily both Hymettus areas. In most of these cases quite clear thresholds can be defined particularly for the high probability of flooding. These graphs are also consistent regarding the distribution of the flash flood event concentration, which tends to increase as we move to higher 

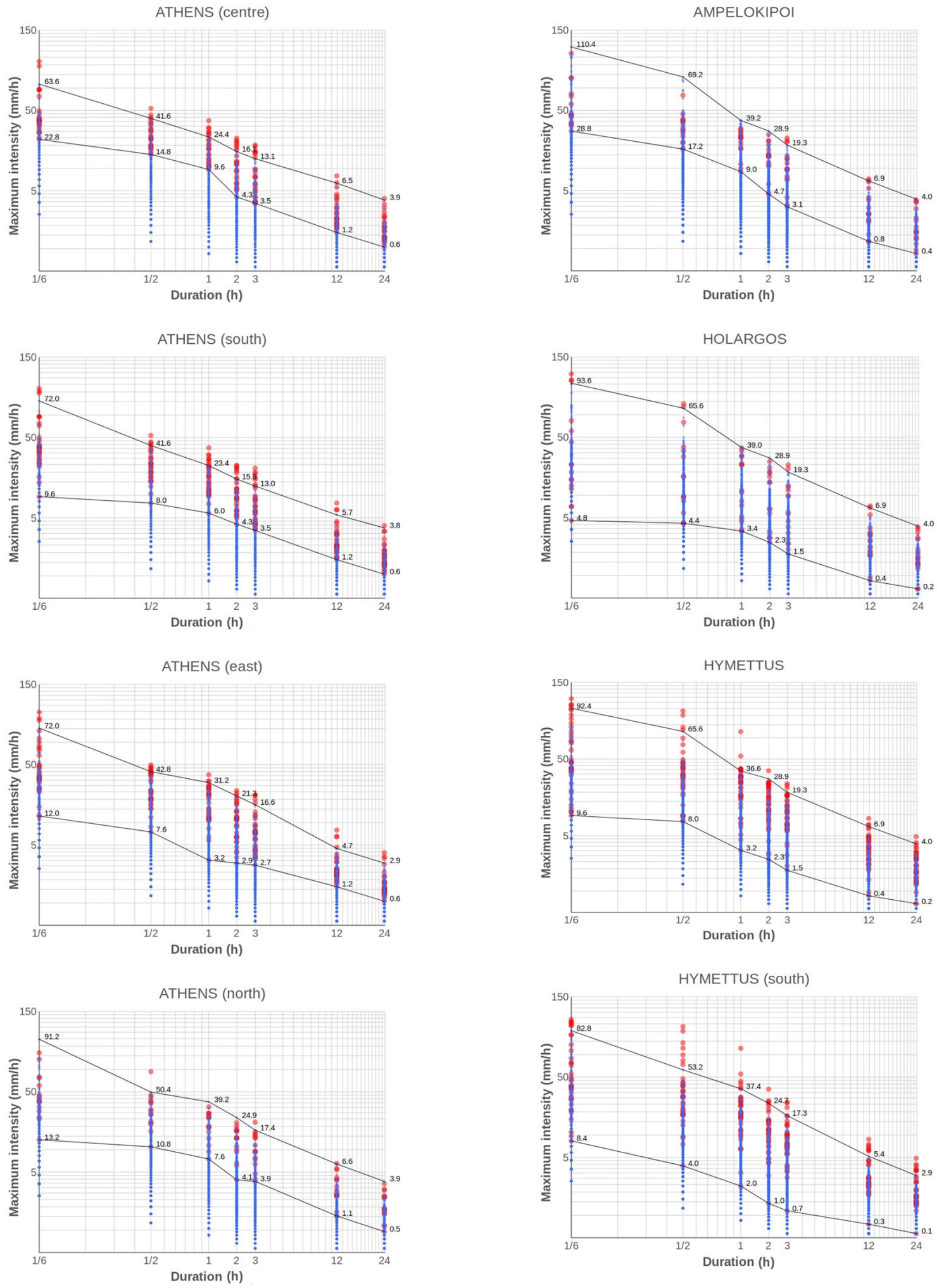

Figure 7. 

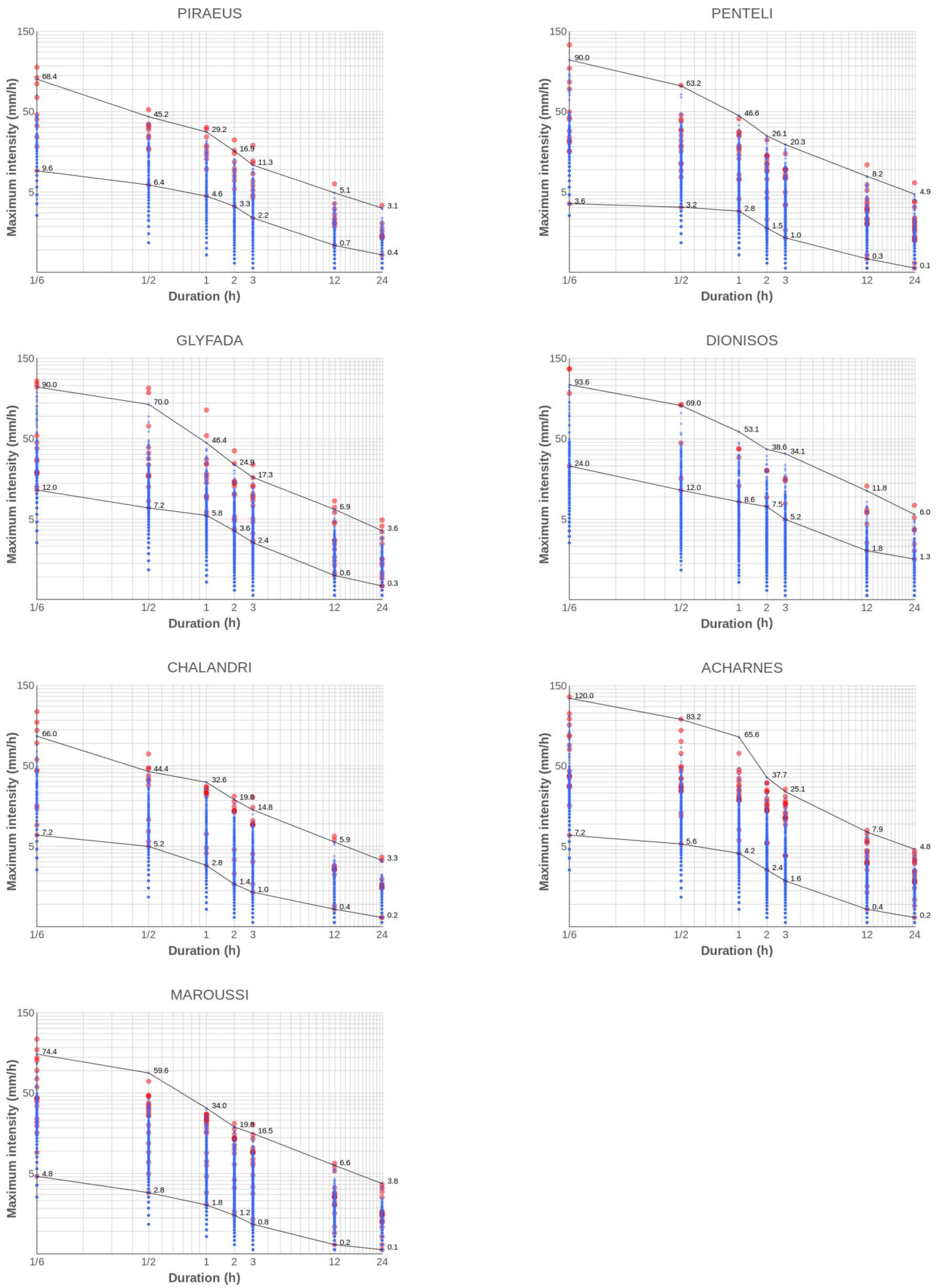

Figure 7. Peak rainfall intensities versus duration graphs, at each sub-area shown in Fig. 2. Peak intensities for each sub-area derive from the rainfall data recorded by all the representative rain gauges shown in Fig. 2. Red dots represent the events that led to reported flooding. All graphs use logarithmic $x$ axis scale. 
rainfall intensity values. Contrariwise, areas such as Holargos and Glyfada are obviously not well represented by the existing rain gauges since their graphs present a wide and inconsistent spread of peak intensities. Low representativity is related either to the small operation record of rain gauges or to the local density of stations, in some cases too low to cover adequately the entire area. It is also possible that some areas demonstrate particular vulnerability in some places that are prone to flooding even for low rainfall intensity. To capture the specific local sensitivities to rainfall, it is obvious that a denser network of rain gauges is required. This applies in the areas of Chalandri and Maroussi, and it is even more necessary for Acharnes, Penteli and Dionisos due to the topographic features of the mountainous areas.

The areas of Ampelokipoi and Athens centre, opposite of what we would expect for the most intensively urbanized areas, present a high rainfall intensity threshold above which flooding is likely to occur. Specifically, in the area of Ampelokipoi no damaging flash flood occurred for a peak intensity less than $29 \mathrm{~mm} \mathrm{~h}^{-1}$ for $10 \mathrm{~min}$ duration or $9 \mathrm{~mm} \mathrm{~h}^{-1}$ for $1 \mathrm{~h}$ duration. Even though distribution of population has been found to be relevant to the frequency of flash flood events, it can only partly explain the flash flood thresholds. The threshold value - in other words the hazard intensity needed for a place to flood - may also be related to other factors, such as the drainage system effectiveness and the preparedness of the local authorities (Barrera-Escoda and Llasat, 2015). Therefore, there is not one simple answer to what the key drivers are behind vulnerability of an area. For highly urbanized areas like the centre of Athens there is land cover and population density on the one hand, while on the other hand, as discussed also by Brody et al. (2012), a more coordinated system of flood mitigation infrastructure due to greater resources may exist. Although the centre of Athens is not likely to flood if rainfall intensity is less than $22.8 \mathrm{~mm} \mathrm{~h}^{-1}$ for $10 \mathrm{~min}$ duration or $9.6 \mathrm{~mm} \mathrm{~h}^{-1}$ for $1 \mathrm{~h}$ duration, it floods for intensities, of $63.3 \mathrm{~mm} \mathrm{~h}^{-1}$ for $10 \mathrm{~min}$ duration or $24.4 \mathrm{~mm} \mathrm{~h}^{-1}$ for $1 \mathrm{~h} \mathrm{du}$ ration, that are lower than the respective intensities for which other areas flood, showing a lower resistance of the system. Low threshold values above which flooding is most probable could indicate some limits in the existing infrastructure to cope with the growth of population and materials exposed and, in any case, confirm the necessity for additional protection measures and for the development of an effective warning system.

According to the European Environmental Agency (EEA, 2010), the improvement of forecasting and early-warning systems is seen as the most effective way to mitigate the effects of flash floods. Early warning for flash floods is provided in Greece, based on the weather forecasts, and it is communicated via the media. However, not only the spatial scale of the numerical weather prediction models but also the uncertainty in the quantitative precipitation forecasts do not allow for the risk estimation at local level. For that reason, a dense network of automatic surface meteorological stations providing real-time $10 \mathrm{~min}$ accumulated rainfall and intensity observations could constitute a supplementary tool for early warning. Standardization of regional rainfall thresholds in several time intervals could therefore be a very useful tool during a rainfall event. Evidently, what is required in order to produce reliable thresholds on a local level is a denser network of rain gauges as well as long-period data. According to the rain intensity-duration graphs produced in the present study, the rainfall thresholds for flood triggering for the areas around Athens city and Hymettus could be used for the needs of an early-warning system, while for the other areas under examination a denser rain gauge network is required in order to obtain more robust results.

\section{Concluding remarks}

The objective of this study was to perform an analysis of the flash flood occurrence in an urbanized region, in an effort to identify triggering rainfall thresholds, as well as the effect of the rainfall hazard indicators to the magnitude of the induced impact, considering factors that influence the local vulnerability, such as the population distribution and the geographical features. A major contribution of this paper is that it provides extensive information on the flash flood events of a 10-year period, at the very local level of the most highly urbanized area of Greece, the urban part of the Attica prefecture. This information is considered particularly useful in the context of an integrated approach of the assessment and management of flood risks (EEA, 2010). Moreover, the synthesis of flash flood impact data and complete rainfall records allows the investigation of local rainfall thresholds related to the occurrence of damaging flooding.

Almost all the damaging flash flood events in the target area that occurred during the period 2005-2014 were associated with maximum accumulated rainfall of more than $20 \mathrm{~mm}$ in $24 \mathrm{~h}$ and $3 \mathrm{~mm}$ in $10 \mathrm{~min}$. However, the flash flood impact intensity, as measured by the number of fire service operations per event, increases significantly above the level of $60 \mathrm{~mm}$ in $24 \mathrm{~h}$ and $10 \mathrm{~mm}$ in $10 \mathrm{~min}$. It is interesting that Barbería at al. (2014), in their study on the role of factors related to the social impact of heavy-rain events in the city of Barcelona, examined the maximum $24 \mathrm{~h}$ rainfall paying special attention to the rainfall between 40 and $60 \mathrm{~mm}$ and the rainfall exceeding $60 \mathrm{~mm}$, especially for the areas with high population density. These thresholds have been found to be significant in what concerns the magnitude of the flash flood impact in an urban environment. They also found good correlation of the maximum rainfall recorded in short time intervals (10 and $30 \mathrm{~min}$ ) with the impact indicators. In the present study, rainfall in short time intervals has been proved to be a good indicator of the induced impact only when the analysis is performed on a more local scale and provided that a sufficient network of rain gauges exists in the examined area. 
The most robust results in what concerns the rainfall intensity thresholds have been produced for the centre of Athens, the area that suffers most from damaging flash flood events. The respective rain gauges have been found to be representative of the area, and the estimated thresholds indicate that the city centre manages to resist very low rainfall intensities, but its resistance has a certain limit above which flooding seems to be the most probable scenario. It is in the authors' future plans to evaluate in practice the rainfall thresholds estimated and improve their reliability by the increase in the precipitation data series, as well as the expansion of the meteorological network.

Consideration of the local particularities led to conclusions regarding the rainfall hazard at a local level and the implication of urbanization for the coping capacity. The analysis showed that reliability of these thresholds depends a lot on the representativity of the existing rain gauge network in terms of density, location and record length. The ongoing expansion of the network operated by the National Observatory of Athens ensures the future collection of long-term data, which will enhance the accuracy of defined rainfall thresholds associated with flooding and will permit further assessment of changes in the communities' exposure and resiliency.

Acknowledgements. This research has been partly financed by the "Development Proposals of Research Entities - KRIPIS" framework, which is funded by National Programme "Competitiveness and Entrepreneurship", Action: "THESPIA - Development of synergistic and integrated methods and tools for monitoring, management and forecasting of Environmental parameters and pressures". The authors acknowledge the Hellenic Fire Service for the provision of statistical data on the operations made due to harmful weather events. Finally the Laboratory of Hydrology and Water Resources Management of the National Technical University of Athens is acknowledged for the supply of precipitation measurements from 10 stations in the study area.

Edited by: B. D. Malamud

Reviewed by: M. Mergili and one anonymous referee

\section{References}

Amaro, J., Gayà, M., Aran, M., and Llasat, M. C.: Preliminary results of the Social Impact Research Group of MEDEX: the request database (2000-2002) of two Meteorological Services, Nat. Hazards Earth Syst. Sci., 10, 2643-2652, doi:10.5194/nhess-10-2643-2010, 2010.

Barberia, L., Amaro, J., Aran, M., and Llasat, M. C.: Social impact analysis of two heavy rain events in Catalonia: 14 and 15 July 2001 and 3 April 2002, Plinius Conference on Mediterranean Storms, Disasters and Climate Change: knowing how to adapt, Savona, Italy, 7-9 September 2011, Programme Book, contribution 13-57, 2011.

Barbería, L., Amaro, J., Aran, M., and Llasat, M. C.: The role of different factors related to social impact of heavy rain events: considerations about the intensity thresholds in densely populated areas, Nat. Hazards Earth Syst. Sci., 14, 1843-1852, doi:10.5194/nhess-14-1843-2014, 2014.

Barrera-Escoda, A. and Llasat, M. C.: Evolving flood patterns in a Mediterranean region (1301-2012) and climatic factors the case of Catalonia, Hydrol. Earth Syst. Sci., 19, 465-483, doi:10.5194/hess-19-465-2015, 2015.

Bracken, L. J., Cox, N. J., and Shannon, J.: The relationship between rainfall inputs and flood generation in south-east Spain, Hydrol. Process., 22, 683-696, doi:10.1002/hyp.6641, 2008.

Brody, S. D., Blessing, R., Sebastian, A., and Bedient, P.: Delineating the reality of flood risk and loss in Southeast Texas, Natural Hazards Review, 14, 89-97, 2012.

Cannon, S. H., Gartner, J. E., Wilson, R. C., Bowers, J. C., and Laber, J. L.: Storm rainfall conditions for floods and debris flows from recently burned areas in southwestern Colorado and southern California, Geomorphology, 96, 250-269, doi:10.1016/j.geomorph.2007.03.019, 2008.

Carpenter, T., Sperfslage, J., Georgakakos, K., Sweeney, T., and Fread, D.: National threshold runoff estimation utilizing GIS in support of operational flash flood warning systems, J. Hydrol., 224, 21-44, 1999

CRED: Disaster data: A balanced perspective, CRED Crunch, Centre for Research on the Epidemiology of Disasters, Issue No. 17, Brussels, 2009.

Diakakis, M.: Rainfall thresholds for flood triggering. The case of Marathonas in Greece, Nat. Hazards, 60, 789-800, doi:10.1007/s11069-011-9904-7, 2012.

Diakakis, M., Mavroulis, S., and Deligiannakis, G.: Floods in Greece, a statistical and spatial approach, Nat. Hazards, 62, 485500, doi:10.1007/s11069-012-0090-z, 2012.

Du, S., Shi, P., Van Rompaey, A. and Wen, J.: Quantifying the impact of impervious surface location on flood peak discharge in urban areas, Nat. Hazards, 76, 1457-1471, doi:10.1007/s11069014-1463-2, 2015.

EEA: Mapping the impacts of natural hazards and technological accidents in Europe, European Environmental Agency, Technical report No. 13/2010, Copenhagen, doi:10.2800/62638, 2010.

Gaume, E., Bain, V., Bernardara, P., Newinger, O., and Barbuc, M.: A compilation of data on European flash floods, J. Hydrol., 367, 70-78, 2009.

Georgakakos, K.: Analytical results for operational flash flood guidance, J. Hydrol., 317, 81-103, doi:10.1016/j.jhydrol.2005.05.009, 2006.

Guzzetti, F., Peruccacci, S., Rossi, M., and Stark, C. P.: The rainfall intensity-duration control of shallow landslides and debris flows: an update, Landslides, 5, 3-17, doi:10.1007/s10346-007-0112-1, 2008 .

HAIC: Natural Hazards and Riots in Greece 1993-2014, Hellenic Association of Insurance Companies, Athens, 2015.

Jansa, A., Alpert, P., Arbogast, P., Buzzi, A., Ivancan-Picek, B., Kotroni, V., Llasat, M. C., Ramis, C., Richard, E., Romero, R., and Speranza, A.: MEDEX: a general overview, Nat. Hazards Earth Syst. Sci., 14, 1965-1984, doi:10.5194/nhess-14-19652014, 2014.

Jonkman, S. N.: Global Perspectives on Loss of Human Life Caused by Floods, Nat. Hazards, 34, 151-175, doi:10.1007/s11069-0048891-3, 2005. 
Kandilioti, G. and Makropoulos, C.: Preliminary flood risk assessment: the case of Athens, Nat. Hazards, 61, 441-468, doi:10.1007/s11069-011-9930-5, 2012.

Kotroni, V., Lagouvardos, K., Kallos, G., and Ziakopoulos, D.: Severe flooding over central and southern greece associated with pre-cold frontal orographic lifting, Q. J. Roy. Meteor. Soc., 125, 967-991, doi:10.1002/qj.49712555511, 1999.

Koussis, A., Lagouvardos, K., Mazi, K., Kotroni, V., Sitzmann, D., Lang, J., Zaiss, H., Buzzi, A., and Malguzzi, P: Flood Forecasts for Urban Basin with Integrated Hydro-Meteorological Model, J. Hydrol. Eng., 8, 1-11, 2003.

Lagouvardos, K. and Kotroni, V.: TRMM and Lightning Observations of a Low-Pressure System over the Eastern Mediterranean, B. Am. Meteorol. Soc., 88, 1363-1367, doi:10.1175/bams-88-91363, 2007.

Lagouvardos, K., Kotroni, V., Dobricic, S., Nickovic, S., and Kallos, G.: The storm of October 21-22, 1994, over Greece: Observations and model results, J. Geophys. Res.-Atmos., 101, $26217-$ 26226, doi:10.1029/96jd01385, 1996.

Lastoria, B., Simonetti, M. R., Casaioli, M., Mariani, S., and Monacelli, G.: Socio-economic impacts of major floods in Italy from 1951 to 2003, Adv. Geosci., 7, 223-229, 2006, http://www.adv-geosci.net/7/223/2006/

Llasat, M. C., López, L., Barnolas, M., and Llasat-Botija, M.: Flashfloods in Catalonia: the social perception in a context of changing vulnerability, Adv. Geosci., 17, 63-70, 2008, http://www.adv-geosci.net/17/63/2008/.

Llasat, M. C., Llasat-Botija, M., Barnolas, M., López, L., and Altava-Ortiz, V.: An analysis of the evolution of hydrometeorological extremes in newspapers: the case of Catalonia, 1982-2006, Nat. Hazards Earth Syst. Sci., 9, 1201-1212, doi:10.5194/nhess-9-1201-2009, 2009.

Llasat, M. C., Llasat-Botija, M., Petrucci, O., Pasqua, A. A., Rosselló, J., Vinet, F., and Boissier, L.: Towards a database on societal impact of Mediterranean floods within the framework of the HYMEX project, Nat. Hazards Earth Syst. Sci., 13, 13371350, doi:10.5194/nhess-13-1337-2013, 2013.
Martina, M. L. V., Todini, E., and Libralon, A.: A Bayesian decision approach to rainfall thresholds based flood warning, Hydrol. Earth Syst. Sci., 10, 413-426, doi:10.5194/hess-10-413-2006, 2006.

Norbiato, D., Borga, M., and Dinale, R.: Flash flood warning in ungauged basins by use of the flash flood guidance and model-based runoff thresholds, Meteorol. Appl., 16, 65-75, doi:10.1002/met.126, 2009.

Papagiannaki, K., Lagouvardos, K., and Kotroni, V.: A database of high-impact weather events in Greece: a descriptive impact analysis for the period 2001-2011, Nat. Hazards Earth Syst. Sci., 13, 727-736, doi:10.5194/nhess-13-727-2013, 2013.

Price, C., Yair, Y., Mugnai, A., Lagouvardos, K., Llasat, M. C., Michaelides, S., Dayan, U., Dietrich, S., Di Paola, F., Galanti, E., Garrote, L., Harats, N., Katsanos, D., Kohn, M., Kotroni, V., Llasat-Botija, M., Lynn, B., Mediero, L., Morin, E., Nicolaides, K., Rozalis, S., Savvidou, K., and Ziv, B.: Using Lightning Data to Better Understand and Predict Flash Floods in the Mediterranean, Surv. Geophys., 32, 733-751, doi:10.1007/s10712-0119146-y, 2011a.

Price, C., Yair, Y., Mugnai, A., Lagouvardos, K., Llasat, M. C., Michaelides, S., Dayan, U., Dietrich, S., Galanti, E., Garrote, L., Harats, N., Katsanos, D., Kohn, M., Kotroni, V., Llasat-Botija, M., Lynn, B., Mediero, L., Morin, E., Nicolaides, K., Rozalis, S., Savvidou, K., and Ziv, B.: The FLASH Project: using lightning data to better understand and predict flash floods, Environ. Sci. Policy, 14, 898-911, doi:10.1016/j.envsci.2011.03.004, 2011 b.

Špitalar, M., Gourley, J. J., Lutoff, C., Kirstetter, P.-E., Brilly, M., and Carr, N.: Analysis of flash flood parameters and human impacts in the US from 2006 to 2012, J. Hydrol., 519, 863-870, doi:10.1016/j.jhydrol.2014.07.004, 2014.

Tsakiris, G.: Flood risk assessment: concepts, modelling, applications, Nat. Hazards Earth Syst. Sci., 14, 1361-1369, doi:10.5194/nhess-14-1361-2014, 2014. 